\title{
Density functional theory calculations of charge transport properties of 'plate-like' coronene topological structures
}

\author{
ZIRAN CHEN ${ }^{\mathrm{a}}$, ZHANRONG HE ${ }^{\mathrm{a}}$, YOUHUI XU and WENHAO YU ${ }^{\mathrm{b}, *}$ (D) \\ ${ }^{a}$ Department of Architecture and Environment Engineering, Sichuan Vocational and Technical College, Suining, \\ Sichuan 629000, China \\ ${ }^{\mathrm{b}}$ College of Chemistry and Material Science, Sichuan Normal University, Chengdu, Sichuan 610068, China \\ E-mail: yuwenhao2010@163.com
}

MS received 29 April 2017; revised 25 June 2017; accepted 5 July 2017; published online 4 August 2017

\begin{abstract}
Charge transport rate is one of the key parameters determining the performance of organic electronic devices. In this paper, we used density functional theory (DFT) at the M06-2X/6-31+G(d) level to compute the charge transport rates of nine coronene topological structures. The results show that the energy gap of these nine coronene derivatives is in the range $2.90-3.30 \mathrm{eV}$, falling into the organic semiconductor category. The size of the conjugate ring has a large influence on the charge transport properties. Incorporation of methyl groups on the rigid core of tetrabenzocoronene and hexabenzocoronene is more conducive to the hole transport of the molecule than incorporating methoxyl groups. The derivatisation of a 'long plate-like' coronene with methoxyl groups facilitates both hole and electron transport. This class of molecules can thus be used in the design of ambipolar transport semiconductor materials.
\end{abstract}

Keywords. Organic semiconductors; density functional theory; charge carrier mobility; ambipolar transport; coronene derivatives; topological structures.

\section{Introduction}

Organic semiconductor materials have attracted great interest from scientists for the past half century due to their light-weight nature and good flexibility. ${ }^{1}$ They can be used to create solution-processed printed electronics and hold the promise of low-cost thin-film devices, including organic photovoltaic devices, ${ }^{2,3}$ organic lightemitting diodes and organic field-effect transistors. ${ }^{4}$ To be suitable for high-performance devices, organic semiconductors must possess desirable characteristics such as good solubility in organic solvents, molecular self-assembly, and high charge transport rate. In recent years, the two-dimensional ultra-flat material graphene has received much attention in both academia and industry due to its excellent optical and electrical properties. ${ }^{5,6}$ However, its lack of an intrinsic band gap is a major limitation to its further application. On the other hand, the polycyclic aromatic hydrocarbons that make up graphene fragments are favourable due to the tuneable band gaps of their extensive $\pi$ conjugate systems. ${ }^{7,8}$ Polycyclic aromatic hydrocarbons are an important class of organic semiconductor materials.

\footnotetext{
*For correspondence
}

Centred on a polycyclic core, the surrounding flexible side chains can allow the formation of liquid crystalline semiconducting materials. ${ }^{9,10}$ These side chains are usually flexible aliphatic chains, which can be modified to adjust the solubility of the molecule. Common rigid polycyclic cores include pyrene, triphenylene, perylene, truxene, porphyrin, phthalocyanine, and coronene. The rigid polycyclic cores easily self-assemble into columns through $\pi-\pi$ interactions. The charge carriers can move effectively along the axes of the columns via intermolecular $\pi-\pi$ transitions. ${ }^{11,12}$

Coronene derivatives are a class polycyclic aromatic hydrocarbon with high intrinsic carrier mobilities and the potential for use in organic electronic devices. The highly ordered columnar arrangements of hexa-perihexabenzocoronenes with hole mobilities as high as $1.0 \mathrm{~cm}^{2} \mathrm{~V}^{-1} \mathrm{~s}^{-1}$ were first synthesized by Müllen and Spiess, ${ }^{13}$ whereas triphenylene generally has a hole mobility of only $0.1 \mathrm{~cm}^{2} \mathrm{~V}^{-1} \mathrm{~s}^{-114}$ and that of phthalocyanine is slightly higher at $0.7 \mathrm{~cm}^{2} \mathrm{~V}^{-1} \mathrm{~s}^{-1} .{ }^{15}$ The strong $\pi-\pi$ interactions between the rigid cores of the large polycyclic rings provide a more stable columnar structure for charge transport along the columns, enhancing charge transport. In addition, side chain modification has a negligible impact on carrier 
mobility. Both the resonance area of the rigid cores and the distance between them play a significant role in the charge transport properties of organic semiconductor materials. Recently, other topological structures of coronene ring such as tetrabenzo $[a, d, j, m]$ coronene, ${ }^{16}$ hexabenzo $[a, d, g, j, m, p]$ coronene $^{17-20}$ and octabenzocircumbiphenyl ${ }^{21}$ have been synthesized, and their optical properties have been studied experimentally. According to band theory, charge transfer consists of the migration of charge carriers, with the rate of this transfer being one of the key parameters determining the performance of organic electronic devices. ${ }^{22-24}$ Quantum chemistry calculations can predict the thermochemistry, thermodynamics, and photoelectric properties of polycyclic aromatic hydrocarbons. ${ }^{25-27}$ Density functional theory (DFT) is an effective quantum chemistry method for predicting the charge transport rates of novel polycyclic aromatic hydrocarbon molecules to guide future experimental research. ${ }^{28,29}$ Herein, we focus on the use of DFT to investigate the photoelectric properties of polycyclic aromatic hydrocarbons (PAHs), in particular the charge transport properties of discotic liquid crystalline semiconductors. ${ }^{30-33}$ Currently, quantum chemistry calculations mainly focus on the photoelectric properties of simple disk-like or triangular $\mathrm{PAH}$ molecules, ${ }^{34}$ with less work being performed on PAHs with other topological structures. However, as discussed above, the topology of PAHs can significantly affect their photoelectric properties.

In this paper, we used Gaussian 09 E. $01^{35}$ and quantum chemistry methods to study the hole and electron transport properties of the nine coronene topological structures shown in Figure 1, in order to explore the relationship between the molecular charge transport properties and the structures of coronene topological structures. We hope that this will facilitate the synthesis of organic semiconductor materials with excellent electrical properties.

\section{Theoretical methodology}

The mobility of charge carrier $\mu$ can be obtained using the Einstein equation, which is expressed as,

$\mu=\mathrm{e} D /\left(\mathrm{k}_{\mathrm{B}} T\right)$

where $\mathrm{e}$ is the electron charge $\left(1.60 \times 10^{-19} \mathrm{C}\right), \mathrm{k}_{\mathrm{B}}$ is the Boltzmann constant $\left(1.38 \times 10^{-23} \mathrm{~J} / \mathrm{K}\right), T$ is the absolute temperature, and $D$ is the average diffusion coefficient of the charge starting from a molecule and towards all directions in three-dimensional space, as given by Formula (2). The diffusion coefficient is expressed as,

$D=\frac{1}{6} \sum_{i} r_{i}^{2} k_{i} p_{i}$

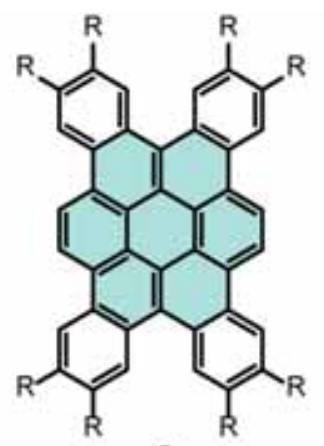

a

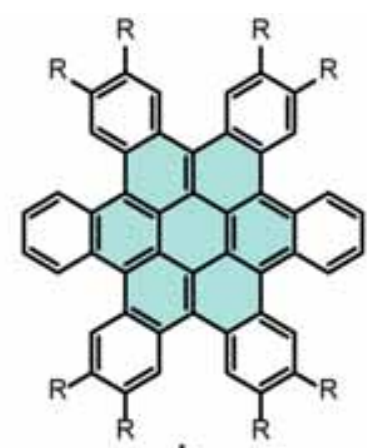

b

a1: $\mathrm{R}=\mathrm{H} ; \mathrm{a} 2: \mathrm{R}=\mathrm{CH}_{3}$ a3: $\mathrm{R}=\mathrm{OCH}_{3}$

b1 $: R=H_{;} ; b 2: R=C_{3}$ b3:R $=\mathrm{OCH}_{3}$

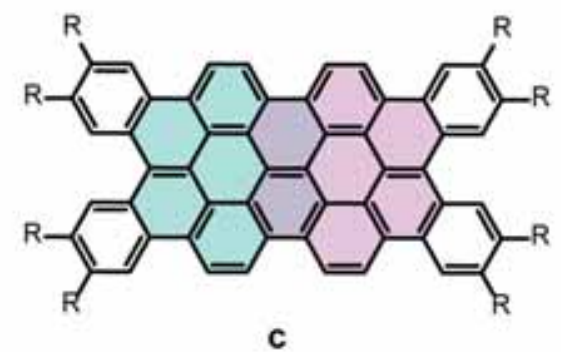

$\mathrm{c} 1: \mathrm{R}=\mathrm{H} ; \mathrm{c} 2: \mathrm{R}=\mathrm{CH}_{3} ; \mathrm{c} 3: \mathrm{R}=\mathrm{OCH}_{3}$

Figure 1. Molecular structures of coronene derivatives. 
where, $r_{i}$ is the distance between adjacent molecules, $k_{i}$ is the charge transfer rate constant between adjacent molecules, and $p_{i}$ is the probability,

$p_{i}=k_{i} / \sum_{i} k_{i}$

of charge transfer to molecule $i$.

The $\pi$-conjugated organic semiconductor materials have the properties of one-dimensional charge carrier migration. The average diffusion coefficient can be simplified as,

$D=\frac{1}{2} r^{2} k$

where $r$ is the disk spacing between adjacent discotic molecules, and $k$ is the charge transfer rate constant between adjacent molecules. The carrier mobility is obtained by substituting into formula (1):

$\mu=k \frac{r^{2}}{2 k_{B} T / e}$

According to the semi-classical model of Marcus charge transfer, ${ }^{28,29}$ the constant of charge transfer rate between adjacent molecules is expressed as the following formula:

$k=\left(4 \pi^{2} / h\right) t^{2}\left(4 \pi \lambda \mathrm{k}_{\mathrm{B}} T\right)^{-0.5} \exp \left[-\lambda /\left(4 \mathrm{k}_{\mathrm{B}} T\right)\right]$

where $\mathrm{h}$ is the Planck constant $\left(6.626 \times 10^{-34} \mathrm{~J} . \mathrm{s}\right), t$ is the charge transfer matrix element, $\lambda$ is the charge reorganization energy, and $\mathrm{T}$ is the absolute temperature. Under a certain temperature, $\lambda$ and $t$ are the main parameters affecting the charge transport rate constant. To achieve a larger charge transport rate constant, the molecule should have smaller reorganization energy $\lambda$ and larger intermolecular charge transport matrix element $t$.

The reorganization energy $\lambda$ was directly calculated using the insulation potential surfaces, that is, the recombination energy $\lambda_{+}$of the transmission hole and the recombination energy $\lambda_{-}$of the transmission electrons are calculated as follows:

$$
\begin{aligned}
\lambda_{+}= & E\left(\mathrm{Ar}^{+} / \mathrm{Ar}\right)-E\left(\mathrm{Ar}^{+} / \mathrm{Ar}^{+}\right)+E\left(\mathrm{Ar} / \mathrm{Ar}^{+}\right) \\
& -E(\mathrm{Ar} / \mathrm{Ar}) \\
\lambda_{-}= & E\left(\mathrm{Ar}^{-} / \mathrm{Ar}\right)-E\left(\mathrm{Ar}^{-} / \mathrm{Ar}^{-}\right)+E\left(\mathrm{Ar} / \mathrm{Ar}^{-}\right) \\
& -E(\mathrm{Ar} / \mathrm{Ar})
\end{aligned}
$$

where $E\left(\mathrm{Ar}^{+} / \mathrm{Ar}\right)$ represents the total energy of the cationic single point energy based on the Ar neutral molecular configuration optimization, and $E\left(\mathrm{Ar}^{+} / \mathrm{Ar}^{+}\right)$represents the total energy when the $\mathrm{Ar}^{+}$ion is optimized configuration.

The charge transfer matrix element characterizes the coupling strength of electron-electron interaction, and several methods have been proposed to evaluate the transfer integral within a molecular dimer. The simplest way is the frontier orbit energy level splitting method. ${ }^{22-24}$ That is, the closed shell system was formed by adding one electron to the molecular/molecular cation system. The energy level splitting of HOMO and HOMO-1 at the transition state was calculated. One half is the hole transfer matrix element $t_{+}$. The closed shell system is formed by removing one electron from the molecular/molecular anion system. The energy level splitting of LUMO and LUMO+1 at the transition state is calculated. One half is the negative charge transfer matrix element $t_{-}$.

\section{Results and Discussion}

\subsection{Molecular design and structural optimization}

Using Gaussian 09 E.01, the molecules shown in Figure 1 were optimized and calculated at M06-2X/6-31 $+\mathrm{G}(\mathrm{d})$ level to obtain their respective stable structures. These molecules included tetrabenzocoronene (series a), hexabenzocoronene (series b), and 'long platelike' coronene (series c), as well as their octamethylsubstituted and octamethoxyl-substituted products. The results show that for the nine molecules, the rigid coronene cores were not coplanar with the peripheral benzene rings, with the three molecules of the $b$ series showing the greatest degree of bending. Figure 2 shows the optimized computational results for the unsubstituted coronene derivatives a1, b1 and $\mathbf{c 1}$.

\subsection{Frontier molecular orbitals}

The frontier orbital energies and electron absorption spectra of the nine molecules were calculated at the same theoretical level as used before. The results are shown in Tables 1 and 2.

The approximate band gaps of organic semiconductors generally fall between 1.4-4.2 eV. From the data of Table 1, one can see that the approximate band gaps of the nine coronene molecules of series $\mathbf{a}, \mathbf{b}$, and $\mathbf{c}$ are between $2.90-3.30 \mathrm{eV}$, which means they are indeed organic semiconductors. The data in Table 1 shows that the HOMO and LUMO levels of the methyl- and methoxyl-substituted molecules in all three series are higher than those of the three unsubstituted molecules (a1, b1 and c1). However, as the increase in energy level is different for the HOMO and LUMO, the resulting approximate band gaps of the molecules decrease. This indicates improved charge migration after the incorporation of methyl and methoxyl groups on the rigid core.

Molecular orbitals play a crucial role in charge migration. ${ }^{29}$ According to our calculations, the HOMO and LUMO electron density distributions are similar for the unsubstituted and methyl-substituted coronene derivatives, with the electron clouds being evenly distributed on the rigid core. Figure 3 shows the frontier molecular orbital diagrams of the HOMOs and LUMOs of the methyl- and methoxyl-substituted molecules in each 


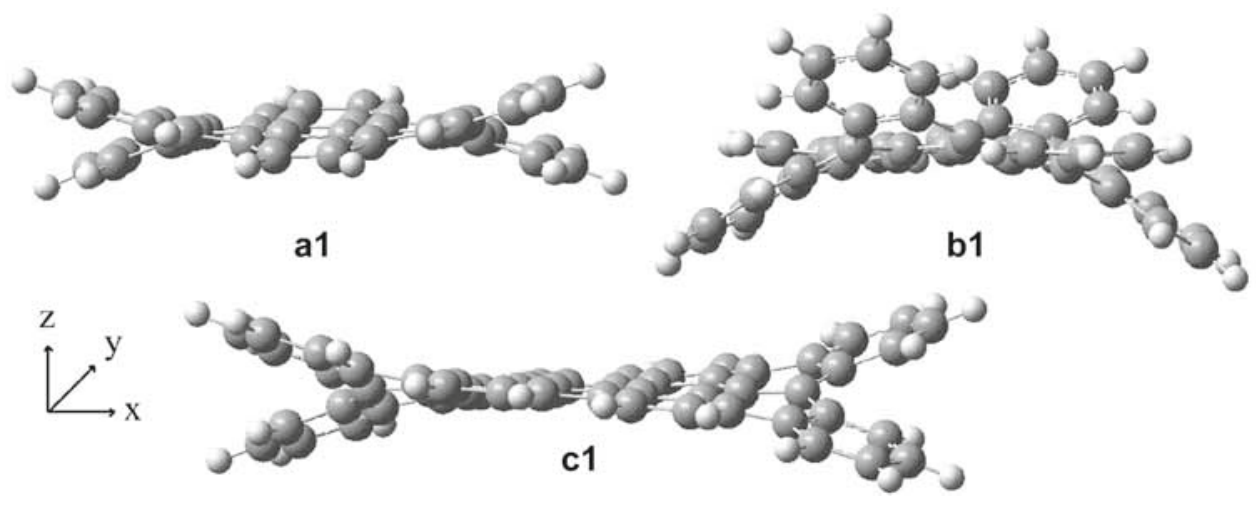

Figure 2. Optimized structures of unsubstituted coronene derivatives a1, b1 and $\mathbf{c 1}$.

Table 1. HOMO-LUMO approximate band gaps (in $\mathrm{eV}$ ) of coronene derivatives.

\begin{tabular}{lccccccccr}
\hline Energy/compound & a1 & a2 & a3 & b1 & b2 & b3 & c1 & c2 & c3 \\
\hline$E_{H}$ & -5.32 & -5.02 & -4.90 & -5.37 & -5.08 & -4.88 & -5.19 & -4.95 & -4.86 \\
$E_{L}$ & -2.12 & -1.84 & -1.72 & -2.07 & -1.83 & -1.75 & -2.28 & -2.05 & -1.97 \\
$E_{g}$ & 3.20 & 3.18 & 3.17 & 3.30 & 3.25 & 3.13 & 2.91 & 2.90 & 2.89 \\
\hline
\end{tabular}

Table 2. Disk spacing distance (nm), charge transport matrix element $t(\mathrm{~kJ} / \mathrm{mol})$, Charge transfer rate constant $\left(\mathrm{s}^{-1}\right)$, and transport rate $\mu\left(\mathrm{cm}^{2} \cdot \mathrm{V}^{-1} \cdot \mathrm{s}^{-1}\right)$ for all nine molecules.

\begin{tabular}{lccccccccc}
\hline Compd. & dis. & $\lambda_{+}$ & $\lambda_{-}$ & $t_{+}$ & $t_{-}$ & $k_{+}$ & $k_{-}$ & $\mu_{+}$ & $\mu_{-}$ \\
\hline a1 & 0.38 & 12.464 & 16.836 & 5.362 & 8.951 & $4.127 \times 10^{13}$ & $6.358 \times 10^{13}$ & 1.133 & 1.754 \\
a1 & 0.45 & 12.464 & 16.836 & 2.852 & 3.495 & $1.168 \times 10^{13}$ & $9.734 \times 10^{12}$ & 0.457 & 0.381 \\
a1 & 0.50 & 12.464 & 16.836 & 1.548 & 1.929 & $2.209 \times 10^{12}$ & $2.966 \times 10^{12}$ & 0.166 & 0.143 \\
a1 & 0.55 & 12.464 & 16.836 & 0.897 & 1.114 & $1.154 \times 10^{12}$ & $9.889 \times 10^{11}$ & 0.067 & 0.069 \\
$\mathbf{a 1}$ & 0.60 & 12.464 & 16.836 & 0.627 & 0.914 & $5.646 \times 10^{11}$ & $6.658 \times 10^{11}$ & 0.039 & 0.046 \\
a2 & 0.55 & 12.921 & 16.680 & 2.510 & 1.367 & $8.507 \times 10^{12}$ & $1.516 \times 10^{12}$ & 0.592 & 0.105 \\
a3 & 0.55 & 20.239 & 22.334 & 0.271 & 2.808 & $3.801 \times 10^{10}$ & $3.145 \times 10^{12}$ & 0.0026 & 0.219 \\
b1 & 0.55 & 10.110 & 14.228 & 1.246 & 1.461 & $3.133 \times 10^{12}$ & $1.104 \times 10^{12}$ & 0.218 & 0.167 \\
b2 & 0.55 & 10.483 & 14.257 & 2.837 & 2.263 & $1.537 \times 10^{13}$ & $5.743 \times 10^{12}$ & 1.071 & 0.400 \\
b3 & 0.55 & 18.046 & 18.935 & 2.590 & 0.563 & $4.572 \times 10^{12}$ & $1.932 \times 10^{11}$ & 0.318 & 0.013 \\
c1 & 0.55 & 10.211 & 13.332 & 0.699 & 0.805 & $9.707 \times 10^{11}$ & $8.986 \times 10^{11}$ & 0.068 & 0.063 \\
c2 & 0.55 & 10.453 & 13.463 & 0.775 & 0.893 & $1.150 \times 10^{12}$ & $9.958 \times 10^{11}$ & 0.080 & 0.069 \\
c3 & 0.55 & 15.472 & 17.416 & 1.523 & 1.784 & $2.210 \times 10^{12}$ & $2.353 \times 10^{12}$ & 0.157 & 0.162 \\
\hline
\end{tabular}

series. As can be seen, the lone pairs of electrons from some of the oxygen atoms on the methoxyl-substituted derivatives contribute to the frontier molecular orbitals, resulting in a relatively large degree of electron delocalization that indicates enhanced charge transport ability. The $\mathrm{HOMO} \rightarrow$ LUMO electronic transitions are from $\pi \rightarrow \pi^{*}$ and $\mathrm{n} \rightarrow \pi^{*}$.

\subsection{Carrier mobilities of the molecules}

The optimized molecular and ionic energies, ionic energies under molecular configurations, and molecular energies under ionic configurations were used to calculate the reorganization energies $\lambda_{+}$and $\lambda_{-}$for hole and electron transport in the nine molecules, as listed in Table 2. When a neutral molecule and a cation of tetrabenzocoronene al completely overlap, they form a dimer. The change of dimer binding energy with disk spacing distance is shown in Figure 4. When the disk spacing distance is between $0.50-0.60 \mathrm{~nm}$, the dimer binding energy tends to be stable. Within this range, small differences are seen between the calculated intermolecular transfer matrix elements for the hole and electron. As the nine coronene molecules have different degrees of planarity, molecule-ion dimer disk spacing 


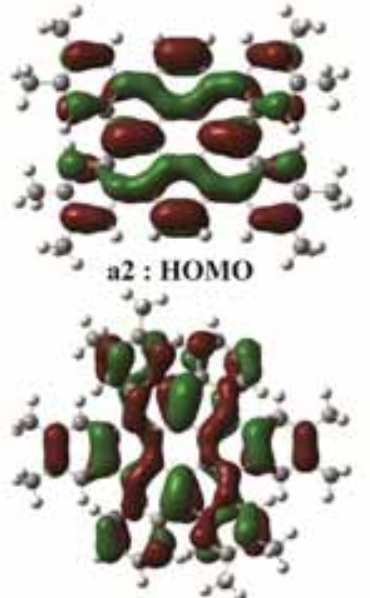

b2 : HONO

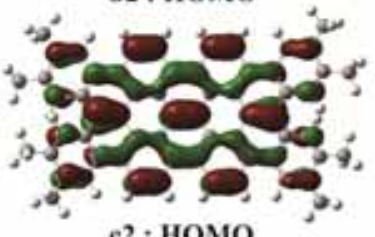

c2 : HOMO
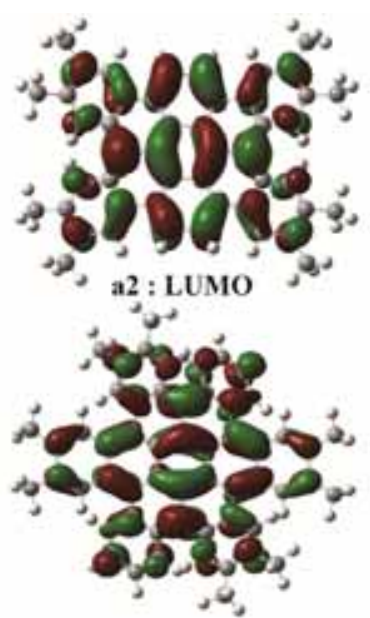

b2 : LUMO

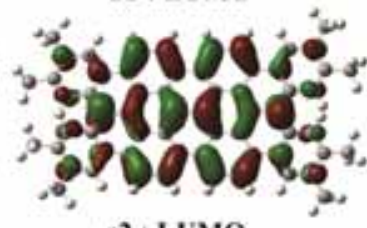

c2 : LUMO
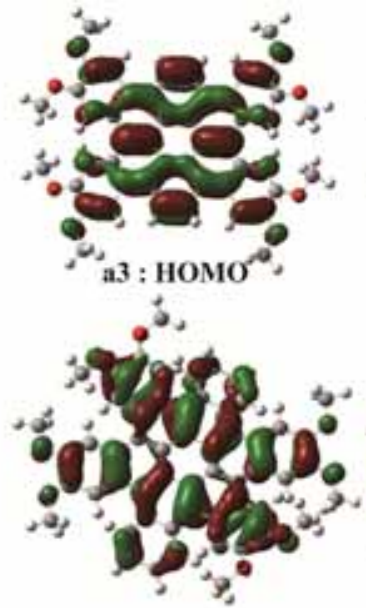

b3 : HOMO

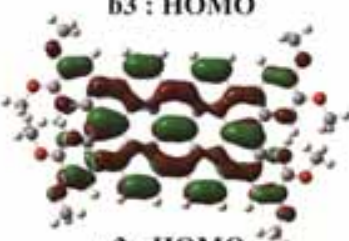

c3: HOMO $^{+2}$,

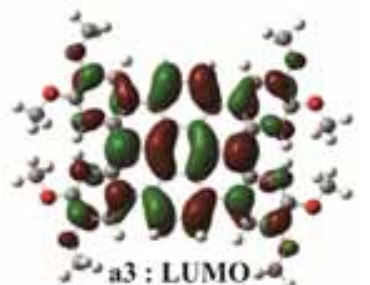

o.

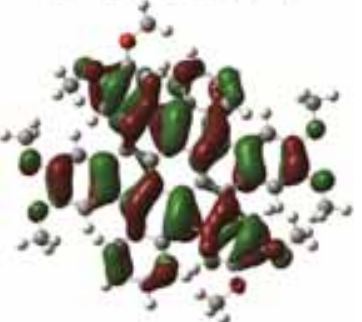

b3 : LUMO

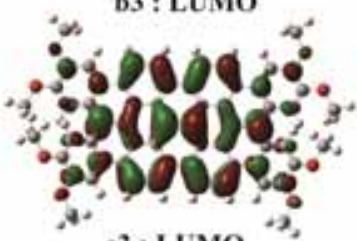

c3 : LUMO

Figure 3. The frontier orbitals of the methyl- and methoxyl-substituted molecules.

distance that is too short could lead to overlapping substituents on the molecule and the ion. So, a disk spacing of $0.55 \mathrm{~nm}$ was chosen for the molecule-ion dimers during the computation of intermolecular transfer matrix elements for the molecules, which was performed to look for trends between molecules from different series. The dihedral angle between the molecule and the ion in the dimer was increased by $20^{\circ}$ steps between 0 $180^{\circ}$ in order to calculate the HOMO/HOMO-1 and LUMO/LUMO+1 energy gaps of the transition-state dimers at different angles. The transfer matrix elements

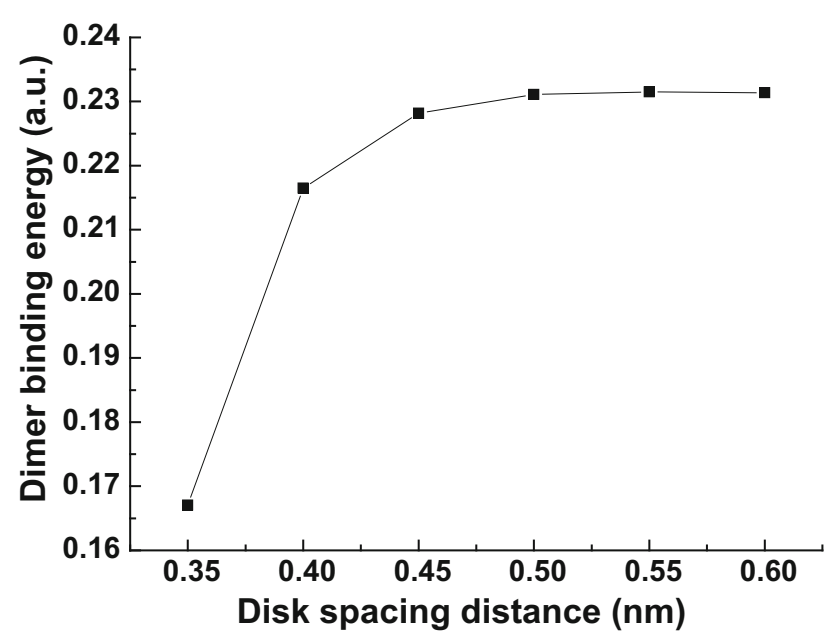

Figure 4. The relationship between the dimer binding energy of a1 dimer molecules and the disk spacing distance. for holes and electrons can be estimated by halving these values. The mean squares of the charge transfer matrix elements of the nine coronene derivatives were calculated using Equation (7) according to the Boltzmann distribution using the energies of the dimers at different dihedral angles $\left(E_{i}\right)$ and the corresponding matrix elements $\left(t_{i}\right)$ at a temperature of $298.15 \mathrm{~K}$. The root of $\left.<t^{2}\right\rangle$ is the charge transfer matrix element, $\mathrm{t}$. The carrier transport rates, $\mu$, were also calculated for the nine molecules using Equations (3) and (4), and the results are shown in Table 2.

$$
\begin{aligned}
& n_{i}=\exp \left(-E_{i} / k \mathrm{~T}\right) / \Sigma_{j} \exp \left(-E_{j} / k T\right) \\
& <t^{2}>=\Sigma_{i} n_{i} t_{i}^{2} \\
& \quad=\Sigma_{i} t_{i}^{2} \exp \left(-E_{i} / k T\right) / \Sigma_{j} \exp \left(-E_{j} / k T\right)
\end{aligned}
$$

From the data in Table 2, one can see that the carrier transport rate decreases with increasing disk spacing distance for the tetrabenzocoronene a1. For the nine molecules in the three series, the reorganization energies for hole and electron transport, $\lambda_{+}$and $\lambda_{-}$, decrease with increasing conjugate area (i.e., in the order $\mathbf{a}>\mathbf{b}>$ c). In each series, the molecules do not change substantially after methyl substitution, but $\lambda_{+}$and $\lambda_{-}$increase significantly for the methoxyl-substituted molecules a3, $\mathbf{b 3}$ and $\mathbf{c 3}$ when compared to the other two members of their respective series. For series $\mathbf{a}$ and $\mathbf{b}$, the methyl-substituted molecules $\mathbf{a} 2$ and $\mathbf{b} \mathbf{2}$ have the largest hole transfer matrix elements due to the relatively 
large degrees of $\pi-\pi$ overlap between neighbouring molecules. The charge transfer rate constants and the carrier mobilities decrease with increasing molecular reorganization energy, and increase with increasing charge transfer matrix elements. As such, the hole transport rates for molecules $\mathbf{a} 2$ and $\mathbf{b} \mathbf{2}$ are the greatest in their respective series. These two species could be used as high-performance hole-transporting (p-type) organic semiconductor materials. Molecules $\mathbf{a 3}$ and b2 have the greatest electron mobilities among the nine molecules studied because of their relatively large electron transfer matrix elements, and thus would make good candidates for electron-transporting materials. Molecules in series $\mathbf{c}$ have poorer $\pi-\pi$ overlap between neighbouring molecules than those in the $\mathbf{a}$ and $\mathbf{b}$ series due to their higher aspect ratios, and they therefore have relatively small charge transfer matrix elements, charge mobilities, and carrier mobilities. However, $\lambda_{+}$and $\lambda_{-}$ and the transfer matrix elements $t_{+}$and $t$ - were close for the holes and electrons of the methoxyl-substituted molecule c3, resulting in similar hole and electron mobilities, which were also the largest in series c. This species could thus be used as an ambipolar organic semiconductor.

\section{Conclusions}

Through structural optimization and quantum chemistry calculations of charge mobilities for nine coronene topological structures belonging to three series, we have learnt that these coronene molecules can be classified as organic semiconductors. The rigid coronene core is not coplanar with the surrounding benzene rings, with the three molecules of series $\mathbf{b}$ being calculated to show the largest degree of bending. The methyl-substituted tetrabenzocoronene $\mathbf{a} 2$ could be a candidate for a holetransporting (p-type) organic semiconductor material. The three molecules of series $\mathbf{b}$ have relatively small reorganization energies for hole and electron transport $\left(\lambda_{+}\right.$and $\left.\lambda_{-}\right)$, and the elements in the intermolecular transfer matrix are relatively large, especially for the methyl-substituted hexabenzocoronene b2, which has the largest hole and electron mobilities seen for any of the nine molecules, at 1.071 and $0.400 \mathrm{~cm}^{2} \cdot \mathrm{V}^{-1} \cdot \mathrm{s}^{-1}$, respectively. This species could therefore be used as a high-performance p-type organic semiconducting material. For molecule $\mathbf{c} 3$, the reorganization energies $\lambda_{+}$and $\lambda_{-}$as well as the intermolecular transfer matrix elements $t_{+}$and $t_{-}$for hole and electron transport were close to each other, leading to similar hole and electron mobilities, which could allow this species to be used as an ambipolar organic semiconductor.

\section{Acknowledgements}

Financial support from the Project of Science and Technology Department of Sichuan Province (Grant Number 2015GZ0343), the Key Project of Sichuan Provincial Department of Education (grant number 17ZA0346) and the Key Foundation of Sichuan Normal University (grant number 15ZD006) are gratefully acknowledged.

\section{References}

1. Bushby R-J, Kelly S-M and O'Neill M 2013 In Liquid crystalline semiconductors (Netherlands: Springer)

2. Schmidt-Mende L, Fechtenkotter A, Müllen K, Moons E, Friend R-H and MacKenzie J-D 2001 Self-organized discotic liquid crystals for high-efficiency organic photovoltaics Science 2931119

3. Kumar M and Kumar S 2017 Liquid crystals in photovoltaics: A new generation of organic photovoltaics Polym. J. 4985

4. Funahashi M 2009 Development of liquid-crystalline semiconductors with high carrier mobilities and their application to thin-film transistors Polym. J. 41459

5. Wu J, Pisula W and Müelle K 2007 Graphenes as potential material for electronics Chem. Rev. 107718

6. Kumar M, Gowda A and Kumar S 2017 Discotic liquid crystals with graphene: supramolecular self-assembly to applications Part. Part. Syst. Char. 1700003

7. Liu Y, Xu Z, Gao W, Cheng Z and Gao C 2017 Graphene and other 2D colloids: Liquid crystals and macroscopic fibers Adv. Mater. 1606794

8. Narayan R, Kim J-E, Kim J-Y, Lee K-E and Kim S-O 2016 Graphene oxide liquid crystals: Discovery, evolution and applications Adv. Mater. 283045

9. Sergeyev S, Pisula W and Geerts Y-H 2007 Discotic liquid crystals: A new generation of organic semiconductors Chem. Soc. Rev. 361902

10. Laschat S, Baro A, Steinke N, Giesselmann F, Hagele C, Scalia G, Judele R, Kapatsina E, Sauer S, Schreivogel A and Tosoni M 2007 Discotic liquid crystals: From tailormade synthesis to plastic electronics Angew Chem. Int. Ed. Engl. 464832

11. Bushby R-J and Lozman O-R 2002 Discotic liquid crystals 25 years on Curr. Opin. Colloid In. 7343

12. Wohrle T, Wurzbach I, Kirres J, Kostidou A, Kapernaum N, Litterscheidt J, Haenle J-C, Staffeld P, Baro A, Giesselmann F and Laschat S 2016 Discotic liquid crystals Chem. Rev. 1161139

13. Van De Craats A-M, Warman J-M, Fechtenkötter A, Brand J-D, Harbison M-A and Müllen K 1999 Record charge carrier mobility in a room-temperature discotic liquid-crystalline derivative of hexabenzocoronene $A d v$. Mater. 111469

14. van de Craats A-M, Warman J-M, de Haas MP, Adam D, Simmerer J, Haarer D and Schuhmacher P 1996 The mobility of charge carriers in all four phases of the columnar discotic material hexakis(hexylthio)triphenylene: Combined TOF and PRTRMC results Adv. Mater. 8823

15. Warman J-M, Kroeze J-E, Schouten P-G and van de Craats A-M 2003 Charge mobility in discotic liquid 
crystalline porphyrins and phthalocyanines measured by PR-TRMC J. Porphyr. Phthalocya. 07342

16. Chen L, Puniredd S-R, Tan Y-Z, Baumgarten M, Zschieschang U, Enkelmann V, Pisula W, Feng X, Klauk H and Müllen K 2012 Hexathienocoronenes: Synthesis and self-organization J. Am. Chem. Soc. 13417869

17. Xiao S-X, Myers M, Miao Q, Sanaur S, Pang K-L, Steigerwald M-L and Nuckolls C 2005 Molecular wires from contorted aromatic compounds Angew. Chem. Int. Ed. Engl. 447390

18. Chiu C-Y, Kim B, Gorodetsky A-A, Sattler W, Wei S, Sattler A, Steigerwald $M$ and Nuckolls C 2011 Shape-shifting in contorted dibenzotetrathienocoronenes Chem. Sci. 21480

19. Wu D, Zhang H, Liang J, Ge H, Chi C, Wu J, Liu S$\mathrm{H}$ and Yin J 2012 Functionalized coronenes: Synthesis, solid structure, and properties J. Org. Chem. 7711319

20. Davy N-C, Man G, Kerner R-A, Fusella M-A, Purdum G-E, Sezen M, Rand B-P, Kahn A and Loo Y-L 2016 Contorted hexabenzocoronenes with extended heterocyclic moieties improve visible-light absorption and performance in organic solar cells Chem. Mater. 28673

21. Xiao S, Kang S-J, Wu Y, Ahn S, Kim J-B, Loo Y-L, Siegrist T, Steigerwald M-L, Li H and Nuckolls C 2013 Supersized contorted aromatics Chem. Sci. 42018

22. Chen X-K, Guo J-F, Zou L-Y, Ren A-M and Fan J-X 2011 A promising approach to obtain excellent n-type organic field-effect transistors: Introducing pyrazine ring J. Phys. Chem. C 11521416

23. Chen X-K, Zou L-Y, Huang S, Min C-G, Ren A-M, Feng J-K and Sun C-C 2011 Theoretical investigation of charge injection and transport properties of novel organic semiconductor materials-cyclic oligothiophenes Org. Electron. 121198

24. Chen X-K, Zou L-Y, Ren A-M and Fan J-X 2011 How dual bridging atoms tune structural and optoelectronic properties of ladder-type heterotetracenes-a theoretical study Phys. Chem. Chem. Phys. 1319490

25. Karton A 2017 How reliable is DFT in predicting relative energies of polycyclic aromatic hydrocarbon isomers? Comparison of functionals from different rungs of jacob's ladder J. Comput. Chem. 38370

26. Chang C-W, Chien F-Y, Hu J-W, Tsai H-Y and Chen K-Y 2017 1,6-Diaminoperylene bisimide with a highly twisted perylene core J. Chem. Sci. 129149

27. Kumar A, Duran M and Solà M 2017 Is coronene better described by Clar's aromatic $\pi$-sextet model or by the AdNDP representation. J. Comput. Chem. doi:10.1002/ jcc. 24801
28. Cornil J, Lemaur V, Calbert J-P and Brédas J-L 2002 Charge transport in discotic liquid crystals: A molecular scale description Adv. Mater. 14726

29. Lemaur V, da Silva Filho D-A, Coropceanu V, Lehmann M, Geerts Y, Piris J, Debije M-G, van de Craats A-M, Senthilkumar K, Siebbeles L-D-A, Warman J-M, Brédas J-L and Cornil J 2004 Charge transport properties in discotic liquid crystals: A quantum-chemical insight into structure-property relationships J. Am. Chem. Soc. 126 3271

30. Chen Z-R and Yu W-H 2017 Theoretical study of the optical and charge transport properties in non-peripherally octasubstituted phthalocyaninetetrabenzoporphyrin hybrids Mol. Phys. 115424

31. Jian L, Tan Y-X, Li Q and Zhao K-Q 2013 Charge transport properties of truxene derivatives molecules Acta Phys. Sin. 62183101

32. Tan Y-X, Liu J-B, Li Q and Zhao K-Q 2015 Charge transfer properties of organic semiconductor molecules of perylene derivatives Chin. J. Struct. Chem. 34335

33. Chen Z-R, Yu W-H and Li Q 2012 Charge transport properties of tetrabenz[a,c,h,j]-anthracene derivatives Chin. J. Struct. Chem. 31851

34. Wang L-J, Xu B, Zhang J-B, Dong Y-J, Wen S-P, Zhang H-Y and Tian W-J 2013 Theoretical investigation of electronic structure and charge transport property of 9,10-distyrylanthracene (DSA) derivatives with high solid-state luminescent efficiency Phys. Chem. Chem. Phys. 152449

35. Frisch M J, Trucks G W, Schlegel H B, Scuseria G E, Robb M A, Cheeseman J R, Montgomery Jr. J A, Vreven T, Kudin K N, Burant J C, Millam J M, Iyengar S S, Tomasi J, Barone V, Mennucci B, Cossi M, Scalmani G, Rega N, Petersson G A, Nakatsuji H, Hada M, Ehara M, Toyota K, Fukuda R, Hasegawa J, Ishida M, Nakajima T, Honda Y, Kitao O, Nakai H, Klene M, Li X, Knox J E, Hratchian H P, Cross J B, Adamo C, Jaramillo J, Gompert, R, Stratmann R E, Yazyev O, Austin A J, Cammi R., Pomelli, C., Ochterski, J.W., Ayala, P.Y., Morokuma, K., Voth, G.A., Salvador, P., Dannenberg, J J, Zakrzewski V G, Dapprich S, Daniels A D, Strain M C, Farkas O, Malick D K, Rabuck A D, Raghavachari K, Foresman J B, Ortiz J V, Cui Q, Baboul A G, Clifford S, Cioslowski J, Stefanov B B, Liu G, Liashenko A, Piskorz P, Komaromi I, Martin R L, Fox D J, Keith T, Al-Laham M A, Peng C Y, Nanayakkara A, Challacombe M, Gill P M W, Johnson B, Chen W, Wong M W, Gonzalez C. and Pople J A 2009 Gaussian 09 Revision B 05 Pittsburgh PA: Program (Wallingford: Gaussian Inc.) 